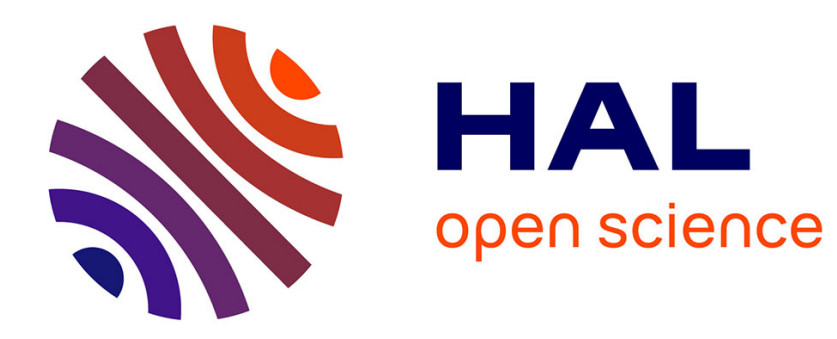

\title{
Active control of laminated plates using a piezoelectric finite element
}

\author{
Isabelle Bruant, F. Pablo, O. Polit
}

\section{To cite this version:}

Isabelle Bruant, F. Pablo, O. Polit. Active control of laminated plates using a piezoelectric finite element. Mechanics of Advanced Materials and Structures, 2008, 15 (3-4), pp.276-290. hal-01366936

\section{HAL Id: hal-01366936 \\ https://hal.science/hal-01366936}

Submitted on 17 Jan 2019

HAL is a multi-disciplinary open access archive for the deposit and dissemination of scientific research documents, whether they are published or not. The documents may come from teaching and research institutions in France or abroad, or from public or private research centers.
L'archive ouverte pluridisciplinaire HAL, est destinée au dépôt et à la diffusion de documents scientifiques de niveau recherche, publiés ou non, émanant des établissements d'enseignement et de recherche français ou étrangers, des laboratoires publics ou privés. 


\title{
Active control of laminated plates using a piezoelectric Finite Element
}

\author{
I Bruant, F Pablo and O Polit \\ LMpX EA 3981, University Paris X-Nanterre, 50 rue de Sèvres 92410 Ville d'Avray, \\ FRANCE \\ E-mail: isabelle.bruant@u-paris10.fr
}

\begin{abstract}
The aim of this work is to develop a simple and very efficient tool, to simulate the active control of laminated plates, and in a next step, to optimize the geometry and number of sensors and actuators. A new piezoelectric Finite Element is presented. It is an eight node plate with one electrical potential degree of freedom for each interface of piezoelectric layers. The usual FSDT theory is combined with a "field compatibility" methodology to avoid the transverse shear locking for thin plates. A LQR control method including a state observer is used to compute the control. Four examples are presented. The quasi-static correction and the use of collocated sensor/actuator are discussed.
\end{abstract}




\section{Introduction}

In recent years, there have been considerable interest and researches in the use of piezoelectric actuators and sensors to control vibrations of plate structures. Vibrations may indeed produce great amplitude fatigue movements, which may be the sources of damage reducing the system performance. Examples of applications are numerous, in particular for light-weight structural systems and high precision machining.

To set up an active control system for a bending structure, many parameters have to be defined:

- the kind of piezoelectric devices: piezoelectric actuators and sensors can be collocated, uncollocated or embedded in the structure,

- the number, location and size of piezoelectric patches: they can be distributed or bonded on the overall structure,

- the control law: several control tools can be used, as the simple constant gain velocity feedback control algorithm as well as a linear quadratic regulator approach,

- the kind of external excitations which induce vibrations: initial conditions, sinusoidal load, step load,...

In this context, the aim of this paper is to present a low cost numerical tool, simple to use and efficient for simulating active control of vibrations. Then, optimization of the number, size, location,... of piezoelectric patches will be studied in this software.

From the literature on active control of plates, some remarks can be pointed out about:

- the kind of smart structures : numerous authors use collocated actuators and sensors, bonded on the overall structure $[1,2,3,4,5,6,7,8,9,10]$. On the other side, actuators and sensors are collocated just on a part of the plate in $[11,12,13,14,15,16,17]$. Finally, actuators and sensors are uncollocated in very few references $[18,19]$.

- the modelling : except for the study of simple structures such as simply supported plates [20, 12], the analytical approach cannot be used. For more complicated plates with integrated piezoelectric materials, finite element (FE) analysis may be required. Some authors propose to use mechanical finite element without any electrical degrees of freedom (dof) [13], when piezoelectric patches are very small. But in the case of piezoelectric embedded in the plate or bonded on the overall structure, electrical dof are needed. A state of this kind of FE is given by [21]. Solid piezoelectric finite element for active control of plates have been mentionned by $[6,18,22]$. ANSYS FE is used by [16]. In [3], the authors develop a triangular element based on the higher order plate theory with 8 mechanical dof per node. Numerous authors use the classical first order shear deformation theory (FSDT). In $[1,11,2,23,8]$, they present triangular or quadrilateral finite elements with one electrical dof per layer. The FE developed by $[7,15]$ can only be used for 
collocated actuators and sensors. In $[8,17,10]$, they use a four nodal element with electrical dof per node. In [14], they define a displacement field for each layer to model laminated plates. In [15], they use a nine nodes element with one electrical dof per element and one temperature degree of freedom.

- the control law : most authors use the simple negative velocity feedback In $[4,14,15,16]$. [7], they compare several control laws and show that LQR optimal control schemes are more effective than classical controls. Their use requires a state space formulation obtained by a structural modal analysis, taking into account the first main modes. Usually, as sensors can only capture a few state variables, a state observer is essential for real-time applications, like a Kalman Filter [16, 7, 14, 15]. In $[19,8]$, they use the independent modal space control which consists in controlling individually specified modes by a LQR algorithm. Finally, in [17], they develop an active control using the $\mathcal{H}_{2}$ control law.

The aim of this work is to present a simple and efficient numerical tool for active control simulations of plates and also (next step) for optimization of piezoelectric locations, size and number [24, 25]. An eight nodes plate finite element is consequently presented, in order to model laminated piezoelectric plates, with one electrical potential degree of freedom for each interface of piezoelectric layers, inducing an electrical layerwise approach in the thickness direction. The displacement approximation is the FSDT theory with only five generalized displacements. But, in order to avoid the transverse shear locking in the thin plate domain, a methodology named "field compatibility" has been used [26]. Combined with pure mechanical FE, this new FE can model elastic plate with some piezoelectric patches. Then, smart configurations presented above can be simulated.

As it is more effective than the negative velocity feedback and because it ensures good stability and robustness [7, 14], the LQR algorithm is used here, including a state observer. Consequently, a modal decomposition is applied to the generalized discret equations. According to the truncation of the modal basis, a static correction can be essential to accurately model the dynamic of the structure [27]. Very few authors consider this additional term in active control, nevertheless only a very few modes are used. In this paper the effect of the static correction is evaluated on some examples.

The first section of this work deals with the finite element formulation. The second part is dedicated to the control system. In the last section, several simulations of active control of plates are presented.

\section{Piezoelectric finite element}

This section is dedicated to composite laminates with piezoelectric layers or patches (embedded or not). The finite element description is detailed in [28] and is briefly recalled hereafter. 


\subsection{The governing equations for piezoelectricity}

Let us consider a plate occupying the domain $\mathcal{P}=\Omega \times\left[-\frac{e}{2} \leq z \leq \frac{e}{2}\right]$ in a Cartesian coordinate system $\left(x_{1}, x_{2}, x_{3}=z\right)$ where $e$ is the constant thickness of the plate $\mathcal{P}$ and $\Omega$ is an arbitrary region in the $\left(x_{1}, x_{2}\right)$ plane. The boundary of the domain is denoted $\partial \mathcal{P}$.

The displacement field with respect to basis vector $\vec{e}_{i}$ and the electric potential are denoted:

$$
\left\{\begin{array}{l}
\vec{u}\left(x_{1}, x_{2}, z, t\right)=\sum_{i=1}^{3} u_{i}\left(x_{1}, x_{2}, z, t\right) \vec{e}_{i} \\
\phi\left(x_{1}, x_{2}, z, t\right)
\end{array}\right.
$$

belonging respectively to the space of admissible displacements $U$ and the space of admissible electric potentials $\Phi$.

Using matrix notations, ( [ ] for matrice and $\{\quad\}$ for vector) the two dimensional constitutive equations of a piezoelectric material are given by:

$$
\left\{\begin{array}{l}
\{T(u)\}=[\bar{C}]\{S(u)\}-[\bar{e}]^{T}\{E(\phi)\} \\
\{D(\phi)\}=[\bar{e}]\{S(u)\}+[\bar{\epsilon}]\{E(\phi)\}
\end{array}\right.
$$

where we denote: the stress vector $\{T(u)\}$, the strain vector $\{S(u)\}$, the electric field vector $\{E(\phi)\}$, the electric displacement vector $\{D(\phi)\}$. Furthermore, in (2), the constitutive bidimensional laws are given by: the elastic stiffness tensor $[\bar{C}]$, the piezoelectric tensor $[\bar{e}]$, the electric permittivity tensor $[\bar{\epsilon}]$. Definitions of those matrices are given in [28] from the three dimensional ones.

Using the above matrix notations and for admissible virtual displacement $\left\{u^{*}\right\} \in$ $U^{*}$ and admissible electric potential $\phi^{*} \in \Phi^{*}$, the electric potential (or field)-based variational principle is given by:

find $(\{u\}, \phi) \in U \times \Phi$ such that:

$$
\begin{gathered}
\int_{\mathcal{P}} \rho\left\{u^{*}\right\}^{T}\{\ddot{u}\} d \mathcal{P}=-\int_{\mathcal{P}}\left\{S^{*}\left(u^{*}\right)\right\}^{T}\{T(u)\} d \mathcal{P}+\int_{\mathcal{P}}\left\{E^{*}\left(\phi^{*}\right)\right\}^{T}\{D(\phi)\} d \mathcal{P}+ \\
\int_{\mathcal{P}}\left\{u^{*}\right\}^{T}\{f\} d \mathcal{P}+\int_{\partial \mathcal{P}_{F}}\left\{u^{*}\right\}^{T}\{F\} d \partial \mathcal{P}-\int_{\mathcal{P}} q \phi^{*} d \mathcal{P}-\int_{\partial \mathcal{P}_{Q}} Q \phi^{*} d \partial \mathcal{P} \\
\forall\left(\left\{u^{*}\right\}, \phi^{*}\right) \in U^{*} \times \Phi^{*}
\end{gathered}
$$

where $\{f\}$ and $\{F\}$ are the prescribed body and surface forces applied on $\partial \mathcal{P}_{F}, q$ and $Q$ are the prescribed body and surface charges applied on $\partial \mathcal{P}_{Q}$ and $\rho$ is the density. Furthermore, $\left\{S^{*}\left(u^{*}\right)\right\}$ and $\left\{E^{*}\left(\phi^{*}\right)\right\}$ are the virtual strain and virtual electric field. (3) is a good starting point for finite element approximations using independent variables $\{u\}$ and $\phi$. 


\subsection{Displacement field approximation}

2.2.1. Displacement field and strains components The kinematic is based on the Reissner-Mindlin plate model:

$$
\left\{\begin{array}{l}
u_{1}\left(x_{1}, x_{2}, z, t\right)=v_{1}\left(x_{1}, x_{2}, t\right)+z \theta_{2}\left(x_{1}, x_{2}, t\right) \\
u_{2}\left(x_{1}, x_{2}, z, t\right)=v_{2}\left(x_{1}, x_{2}, t\right)-z \theta_{1}\left(x_{1}, x_{2}, t\right) \\
u_{3}\left(x_{1}, x_{2}, z, t\right)=v_{3}\left(x_{1}, x_{2}, t\right)
\end{array}\right.
$$

where $v_{\alpha}$ are the membrane displacements with respect to the $x_{\alpha}$ directions, $\theta_{\alpha}$ are the positive rotations of the fiber initially normal to the plate midsurface and $v_{3}$ is the transverse displacement in the normal direction.

Matrix notations can be easily defined using a generalized displacement vector as:

$$
\begin{aligned}
& \{u\}^{T}=\left[F_{u}(z)\right]\left\{\mathcal{E}_{u}\right\} \quad \text { with } \\
& \left\{\mathcal{E}_{u}\right\}^{T}=\left[\begin{array}{lllllllll}
v_{1} & \vdots & v_{2} & \vdots & v_{3} & \vdots & \theta_{1} & \vdots & \theta_{2}
\end{array}\right]
\end{aligned}
$$

and where $\left[F_{u}(z)\right]$ is depending on the normal coordinate $z$. Its expression is given below:

$$
\left[F_{u}(z)\right]=\left[\begin{array}{ccccc}
1 & 0 & 0 & 0 & z \\
0 & 1 & 0 & -z & 0 \\
0 & 0 & 1 & 0 & 0
\end{array}\right]
$$

For small strains, the following expressions are obtained for the strain components:

$$
\begin{aligned}
& S_{11}=v_{1,1}+z \theta_{2,1} \\
& S_{22}=v_{2,2}-z \theta_{1,2} \\
& S_{12}=v_{1,2}+v_{2,1}+z\left(\theta_{2,2}-\theta_{1,1}\right) \\
& S_{23}=v_{3,1}-\theta_{1} \\
& S_{13}=v_{3,2}+\theta_{2}
\end{aligned}
$$

As above for the displacement, the strain components can be described using matrix notation:

$$
\begin{aligned}
& \{S\}=\left[F_{s}(z)\right]\left\{\mathcal{E}_{s}\right\} \quad \text { with } \\
& \left\{\mathcal{E}_{s}\right\}^{T}=\left[\begin{array}{llllllllllllll}
v_{1,1} & v_{1,2} & \vdots & v_{2,1} & v_{2,2} & \vdots & \theta_{1,1} & \theta_{1,2} & \vdots & \theta_{2,1} & \theta_{2,2} & \vdots & S_{23} & S_{13}
\end{array}\right]
\end{aligned}
$$

and where $\left[F_{s}(z)\right]$ is depending on the normal coordinate $z$. Its expression is given below:

$$
\left[F_{s}(z)\right]=\left[\begin{array}{cccccccccc}
1 & 0 & 0 & 0 & 0 & 0 & z & 0 & 0 & 0 \\
0 & 0 & 0 & 1 & 0 & -z & 0 & 0 & 0 & 0 \\
0 & 1 & 1 & 0 & -z & 0 & 0 & z & 0 & 0 \\
0 & 0 & 0 & 0 & 0 & 0 & 0 & 0 & 1 & 0 \\
0 & 0 & 0 & 0 & 0 & 0 & 0 & 0 & 0 & 1
\end{array}\right]
$$


2.2.2. Matrix expression for the weak form From the weak form of the boundary value problem (3), and using (8) and (9), an integration throughout the thickness is performed in order to obtain a bidimensional formulation. Therefore, first right term of (3) can be written under the following form:

$$
\begin{aligned}
& \int_{\mathcal{P}}\left\{S^{*}\left(u^{*}\right)\right\}^{T}\{T(\{u\})\} d \mathcal{P}=\int_{\Omega}\left\{\mathcal{E}_{s}^{*}\right\}^{T}[k]\left\{\mathcal{E}_{s}\right\} d \Omega \text { with } \\
& {[k]=\int_{-e / 2}^{e / 2}\left[F_{s}(z)\right]^{T}[\bar{C}]\left[F_{s}(z)\right] d z}
\end{aligned}
$$

where $[\bar{C}]$ is the constitutive bidimensional law given in [28].

Same calculations for the left member of (3) using (5) and (6) give:

$$
\begin{aligned}
& \int_{\mathcal{P}} \rho\left\{u^{*}\right\}^{T}\{\ddot{u}\} d \mathcal{P}=\int_{\Omega}\left\{\mathcal{E}_{u}^{*}\right\}^{T}[m]\left\{\ddot{\mathcal{E}_{u}}\right\} d \Omega \text { with } \\
& {[m]=\int_{-e / 2}^{e / 2} \rho\left[F_{u}(z)\right]^{T}\left[F_{u}(z)\right] d z}
\end{aligned}
$$

In (10) and (11), the matrices $[k]$ and $[m]$ are the integration throughout the thickness of the material characteristics of the plate.

2.2.3. The geometric approximation The eight-node quadrilateral finite element is presented in figure 1 . The in-plane co-ordinates $\left(x_{1}, x_{2}\right)$ are approximated on the reference bi-unit domain with respect to the reduced coordinates $(\xi, \eta)$ by:

$$
\begin{aligned}
& x_{1}(\xi, \eta)=\sum_{i=1}^{8} N q_{i}(\xi, \eta)\left(x_{1}\right)_{i} \\
& x_{2}(\xi, \eta)=\sum_{i=1}^{8} N q_{i}(\xi, \eta)\left(x_{2}\right)_{i}
\end{aligned}
$$

where $N q_{i}(\xi, \eta)$ are the classical Serendipity interpolation functions, see [26].

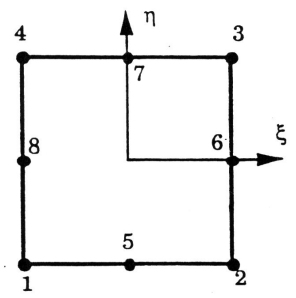

Figure 1. The reference domain of the 8-node finite element.

2.2.4. The displacement approximations From (4), three displacement components $v_{i}$ and two rotations $\theta_{\alpha}$ have to be approximated.

An eight-node quadrilateral plate finite element, with five dof per node, was previously developed and all details are given in $[26,29]$. For the present element, the same displacement approximations are used and briefly described below: 
- for the membrane and bending part of this finite element, an isoparametric procedure is used and the displacements $v_{\alpha}$ and the rotations $\theta_{\alpha}$ are approximated using the same function as the geometry..

- for the transverse shear strains, a methodology named "field compatibility" has been developed in order to avoid the shear locking problem for thin plate. This methodology is briefly described hereafter:

- the transverse shear strains are defined in reduced coordinates:

$$
\gamma_{\xi}=\beta_{\xi}+v_{3, \xi} \quad \gamma_{\eta}=\beta_{\eta}+v_{3, \eta}
$$

where $\beta_{\xi}, \beta_{\eta}$ are rotations in reduced coordinate obtained from the positive rotations $\theta_{\alpha}(\alpha=1,2)$ of $(4)$.

In order to ensure the same polynomial approximation for the rotation and the transverse displacement in (13), $v_{3}$ is assumed to be cubic, introducing four supplementary degree of freedom (dof) at the mid-side nodes: $\left(v_{3, \xi}\right)_{5},\left(v_{3, \eta}\right)_{6},\left(v_{3, \xi}\right)_{7}$, $\left(v_{3, \eta}\right)_{8}$.

- A linear variation of the tangential transverse shear strain component is assumed on each side of the elementary domain. Thus, the supplementary dof introduced at the previous step can be expressed as a linear combination of the rotation and transverse displacement values. Therefore, a new finite element approximation is obtained for the transverse displacement $v_{3}$.

- The interpolation of the reduced transverse shear strain components is defined in the following polynomial basis as the intersection sets of monomial terms from $\xi$ and $\eta$ :

$$
\begin{aligned}
& \mathcal{B}\left(\gamma_{\xi}\right)=\mathcal{B}\left(\beta_{\xi}\right) \cap \mathcal{B}\left(v_{3, \xi}\right)=\left\{1, \xi, \eta, \xi \eta, \eta^{2}\right\} \\
& \mathcal{B}\left(\gamma_{\eta}\right)=\mathcal{B}\left(\beta_{\eta}\right) \cap \mathcal{B}\left(v_{3, \eta}\right)=\left\{1, \xi, \eta, \xi \eta, \xi^{2}\right\}
\end{aligned}
$$

- According to the dimension of the polynomial basis, five points are needed for each reduced transverse shear strains and are presented in figure 2. These points give better results in case of distorted meshes [26]. The following finite element approximation is obtained for the reduced transverse shear strains:

$$
\gamma_{\xi}(\xi, \eta)=\sum_{I=1}^{5} C \xi_{I}(\xi, \eta) \gamma_{\xi I} \quad \gamma_{\eta}(\xi, \eta)=\sum_{J=1}^{5} C \eta_{J}(\xi, \eta) \gamma_{\eta J}
$$

where $C \xi_{I}$ and $C \eta_{J}$ are interpolation functions [26].

- Using the jacobian matrix, the physical transverse shear strains $S_{13}$ and $S_{23}$ are deduced from the reduced transverse shear strains of (15).

2.2.5. The elementary matrices In the previous section, the finite element approximations for the mechanical part were defined and elementary stiffness $\left[K_{u u}^{e}\right]$ 

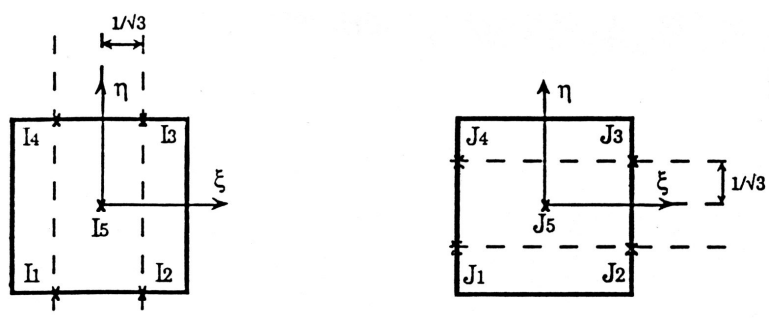

Figure 2. Point locations for the transverse shear strains evaluations.

and mass $\left[M_{u u}^{e}\right]$ matrices can be deduced from respectively (10) and (11). They have the following expression:

$$
\left[K_{u u}^{e}\right]=\int_{\Omega_{e}}[B]^{T}[k][B] d \Omega_{e} \quad\left[M_{u u}^{e}\right]=\int_{\Omega_{e}}[N]^{T}[m][N] d \Omega_{e}
$$

where $[B]$ and $[N]$ are deduced expressing the generalized displacement vectors, see (8) and (5), from the elementary vector of dof denoted $\left\{q_{e}\right\}$ by:

$$
\left\{\mathcal{E}_{s}\right\}=[B]\left\{q_{e}\right\} \quad\left\{\ddot{\mathcal{E}}_{u}\right\}=[N]\left\{\ddot{q}_{e}\right\}
$$

The matrices $[B]$ and $[N]$ contain only the interpolation functions, their derivatives and the jacobian matrix components. In the same way, for the virtual part it gives:

$$
\left\{\mathcal{E}_{s}^{*}\right\}=[B]\left\{q_{e}^{*}\right\} \quad\left\{\mathcal{E}_{u}^{*}\right\}=[N]\left\{q_{e}^{*}\right\}
$$

The same technique can be used defining the elementary mechanical load vector, denoted $\left[B_{u}^{e}\right]$, but it is not detailed here.

\subsection{Electric field approximation}

2.3.1. The electric potential and the electric field vector In active control, each piezoelectric device is considered thin and covered by electrodes at top and bottom faces to ensure the connection with the electric circuit. Then, $\phi$ is assumed constant on each face, and a layerwise linear approximation is used in the thickness direction: calling $\left(\phi_{b o t}^{(k)}, \phi_{t o p}^{(k)}\right)$ the two potential values at the bottom and the top of each layer:

$$
\phi^{(k)}(z(\zeta))=(1-\zeta) \phi_{\text {bot }}^{(k)} / 2+(1+\zeta) \phi_{\text {top }}^{(k)} / 2
$$

where for a layer $(k)$ with thickness $e^{(k)}$ and $z \in\left[z_{b o t}^{(k)}, z_{\text {top }}^{(k)}\right]$, the relation between the thickness coordinate $z$ and the reduce coordinate $\zeta \in[-1,1]$ is given by:

$$
z(\zeta)=\left(z_{\text {bot }}^{(k)}+z_{\text {top }}^{(k)}\right) / 2+\zeta e^{(k)} / 2
$$

Therefore, to prepare the two dimensional weak form for the dielectric part and the coupling between electrical and mechanical effects, we can define for each layer:

$$
\begin{aligned}
& \phi^{(k)}(z(\zeta))=\left[Z_{\phi}(z)\right][C s t]\left[\begin{array}{c}
\phi_{b o t}^{(k)} \\
\phi_{t o p}^{(k)}
\end{array}\right] \text { with } \\
& {\left[Z_{\phi}(z)\right]=\left[\begin{array}{ll}
1 & \zeta
\end{array}\right] \text { and }[C s t]=\left[\begin{array}{rr}
1 / 2 & 1 / 2 \\
-1 / 2 & 1 / 2
\end{array}\right]}
\end{aligned}
$$


For the electric field vector, a relation can be obtained with the same technique:

$$
\begin{aligned}
& -\left\{E^{(k)}(z(\zeta))\right\}=\phi_{, 3}^{(k)} \vec{e}_{3}=\left[Z_{E(}(z)\right][C s t E]\left\{\phi^{(k)}\right\} \vec{e}_{3} \quad \text { with } \\
& {\left[Z_{E(}(z)\right]=\left[\begin{array}{cc}
d \zeta / d z & 0
\end{array}\right]} \\
& {[C s t E]=\left[\begin{array}{cc}
-1 / 2 & 1 / 2 \\
0 & 0
\end{array}\right] \text { and }\left\{\phi^{(k)}\right\}=\left[\begin{array}{c}
\phi_{\text {bot }}^{(k)} \\
\phi_{\text {top }}^{(k)}
\end{array}\right]}
\end{aligned}
$$

$d \zeta / d z=2 / e^{(k)}$ is deduced from $(20)$.

2.3.2. Matrices expressions for the weak form From the weak form of the boundary value problem (3), and using (21) and (22), an integration throughout the thickness is performed in order to obtain the bidimensional formulation. The second term of the right member of (3), introducing (2), can be written under the following form:

$$
\begin{aligned}
& \int_{\mathcal{P}}\left\{E^{*}\left(\phi^{*}\right)\right\}^{T}\{D(\phi)\} d \mathcal{P}=\int_{\mathcal{P}}\left\{E^{*}\left(\phi^{*}\right)\right\}^{T}[\bar{e}]\{S(\{u\})\} d \mathcal{P} \\
& +\int_{\mathcal{P}}\left\{E^{*}\left(\phi^{*}\right)\right\}^{T}[\bar{\epsilon}]\{E(\phi)\} d \mathcal{P}
\end{aligned}
$$

where $[\bar{e}]$ and $[\bar{\epsilon}]$ are the constitutive bidimensional law given in [28].

The first term of the second member in (23) gives the coupling matrix between elastic mechanical and electrical effects while the second term gives the dielectric matrix. Therefore, using (8) for the strain and (22) for the electric field vector, the first term becomes for each layer $(k)$ :

$$
\begin{aligned}
& \int_{\Omega}\left\{\phi^{*(k)}\right\}^{T}[C s t E]^{T}\left[k \phi u^{(k)}\right]\left\{\mathcal{E}_{s}\right\} d \Omega \quad \text { with } \\
& {\left[k \phi u^{(k)}\right]=\int_{z_{\text {bot }}^{(k)}}^{z_{\text {top }}^{(k)}}\left[Z_{E}(z)\right]^{T}[\bar{e}]\left[F_{s}(z)\right] d z}
\end{aligned}
$$

In the same way, introducing matrix notations given by (22), we obtain for the dielectric matrix and for each layer $(k)$ :

$$
\begin{aligned}
& \int_{\Omega}\left\{\phi^{*(k)}\right\}^{T}[C s t E]^{T}\left[k \phi^{(k)}\right][C s t E]\left\{\phi^{(k)\}} d \Omega\right. \text { with } \\
& {\left[k \phi^{(k)}\right]=\int_{z_{\text {bot }}^{(k)}}^{z_{\text {top }}^{(k)}}\left[Z_{E}(z)\right]^{T}[\bar{\epsilon}]\left[Z_{E}(z)\right] d z}
\end{aligned}
$$

In $(24)$ and $(25)$, the matrices $\left[k \phi u^{(k)}\right]$ and $\left[k \phi^{(k)}\right]$ result from the integration throughout the thickness for one layer of the piezoelectric and the dielectric characteristics of the plate.

2.3.3. The elementary matrices At the layer level, the coupling elementary matrix $\left[K_{\phi u}^{e}(k)\right]$ is finally obtained after substituting (18) in (24):

$$
\left[K_{\phi u}^{e}(k)\right]=\int_{\Omega}[C s t E]^{T}\left[k \phi u^{(k)}\right][B u] d \Omega
$$

and from (25), the electric matrix $\left[K_{\phi \phi}^{e}(k)\right]$ is deduced:

$$
\left[K_{\phi \phi}^{e}(k)\right]=\int_{\Omega}[C s t E]^{T}\left[k \phi^{(k)}\right][C s t E] d \Omega
$$


From (26) and (27), a sum on the layers gives the following elementary matrices:

- the coupling matrices $\left[K_{\phi u}^{e}\right]$ and $\left[K_{u \phi}^{e}\right]=\left[K_{\phi u}^{e}\right]^{T}$ from $(26)$;

- the electric matrix $\left[K_{\phi \phi}^{e}\right]$ from $(27)$;

- the electric load vector $\left[B_{\phi}^{e}\right]$ which is not detailed here.

\subsection{Electro-mechanical system equations}

From the weak formulation (3), the representation of the coupled dynamic system can be expressed in a very global compact form as follows:

$$
\left[\begin{array}{cc}
{\left[M_{u u}\right]} & {[0]} \\
{[0]} & {[0]}
\end{array}\right]\left[\begin{array}{l}
\left\{\ddot{q}_{u}\right\} \\
\left\{\ddot{q}_{\phi}\right\}
\end{array}\right]+\left[\begin{array}{cc}
{\left[K_{u u}\right]} & {\left[K_{u \phi}\right]} \\
{\left[K_{\phi u}\right]} & {\left[K_{\phi \phi}\right]}
\end{array}\right]\left[\begin{array}{l}
\left\{q_{u}\right\} \\
\left\{q_{\phi}\right\}
\end{array}\right]=\left[\begin{array}{l}
\left\{B_{u}\right\} \\
\left\{B_{\phi}\right\}
\end{array}\right]
$$

The displacement dof are in the matrix $\left\{q_{u}\right\}$, while $\left\{q_{\phi}\right\}$ contains the electric potential dof.

Assuming that piezoelectric actuators and sensors are bonded or embedded in the structure, the electric potential vector is subdivided in a sensor component $\left\{q_{\phi}^{S}\right\}$ and an actuator component $\left\{q_{\phi}^{A}\right\}$. The external applied electric charge at the sensors is zero. Separating the actuator and sensors sets, the system of (28) becomes:

$$
\begin{aligned}
& {\left[M_{u u}\right]\left\{\ddot{q}_{u}\right\}+\left[K_{u u}\right]\left\{q_{u}\right\}+\left[K_{u \phi}^{S}\right]\left\{q_{\phi}^{S}\right\}=\left\{B_{u}\right\}-\left[K_{u \phi}^{A}\right]\left\{q_{\phi}^{A}\right\}} \\
& {\left[K_{\phi \phi}^{S}\right]\left\{q_{\phi}^{S}\right\}+\left[K_{\phi u}^{S}\right]\left\{q_{u}^{S}\right\}=[0]}
\end{aligned}
$$

$\left[K_{u \phi}^{S}\right],\left[K_{\phi \phi}^{S}\right]$ and $\left[K_{u \phi}^{A}\right]$ are the generalized discrete matrices for sensors and actuators.

Substituting $\left\{q_{\phi}^{S}\right\}$ in (29) by its expression obtained from (30) gives:

$$
\left[M_{u u}\right]\left\{\ddot{q}_{u}\right\}+\left(\left[K_{u u}\right]-\left[K_{u \phi}^{S}\right]\left[K_{\phi \phi}^{S}\right]\left[K_{\phi u}^{S}\right]\right)\left\{q_{u}\right\}=\left\{B_{u}\right\}-\left[K_{u \phi}^{A}\right]\left\{q_{\phi}^{A}\right\}
$$

In the case where piezoelectric sensors are small compared to the size of the structure, the added rigidity in (31) can be neglected. In addition to these equations, initial conditions have to be used.

In order to set up a control law to damp the vibrations caused by external disturbances $\left\{B_{u}\right\}$ or by initial conditions, a state space model is developed in the next section and a linear quadratic regulator (LQR) method, including a state observer is used.

\section{The control system}

The application of the active control methods in a dynamic structural problem requires the use of a state space model. To obtain this kind of equation, the solution $\left\{q_{u}\right\}$ is decomposed into the normalized orthogonal structural modal basis $\left\{\psi_{n}\right\}$. 


\subsection{Modal analysis}

Assuming that the system response is governed by the $N$ first eigenfunctions, the displacement can be expressed by:

$$
\left\{q_{u}\right\}=\sum_{n=1}^{N}\left\{\psi_{n}\right\} \alpha_{n}(t)=[\Psi]\{\alpha\}
$$

where $[\Psi]$ is the modal shape matrix and $\{\alpha\}$ is a vector (size: $(N, 1)$ ). Substituting this equation into (30) and (31), and using the orthogonality properties of modes leads to the following equations:

$$
\begin{aligned}
& \{\ddot{\alpha}\}+2[\delta][\omega]\{\alpha\}+[\omega]^{2}\{\alpha\}=[\Psi]^{T}\left\{B_{u}\right\}-\{\psi\}^{T}\left[K_{u \phi}^{A}\right]\left\{q_{\phi}^{A}\right\} \\
& \left\{q_{\phi}^{S}\right\}=-\left[K_{\phi \phi}^{S}\right]^{-1}\left[K_{\phi u}^{S}\right][\Psi]\{\alpha\}
\end{aligned}
$$

A term of modal viscous damping has been added to take into account a small amount of natural damping without coupling the modes. $[\delta]$ is the diagonal matrix of damping ratio and $[\omega]$ is the diagonal matrix containing the natural angular frequencies.

These $N$ equations can be written in a state space form. Using the state vector $($ size $2 N)$

$$
\{x\}=\left\{\omega_{n} \alpha_{n} \dot{\alpha}_{n}\right\}^{T}
$$

and considering, $N_{A}$ actuators and $N_{S}$ sensors, yields

$$
\begin{aligned}
& \{\dot{x}\}=[A]\{x\}+[B]\left\{q_{\phi}^{A}\right\}+\{g\} \\
& \{x\}(t=0)=\left\{x_{0}\right\}, \quad\{y\}=\left\{q_{\phi}^{S}\right\}=[C]\{x\}
\end{aligned}
$$

$[A]_{2 N, 2 N},[B]_{2 N, N_{A}},[C]_{N_{S}, 2 N}$ and $\{g\}_{2 N, 1}$ are the state, control, output and load matrices, given by:

$$
\begin{aligned}
& {[A]=\left[\begin{array}{cc}
{[0]} & {[\omega]} \\
{[-\omega]} & {[0]}
\end{array}\right] \quad[B]=\left[\begin{array}{c}
{[0]} \\
{[\Psi]^{T}\left[K_{u \phi}^{A}\right]}
\end{array}\right]} \\
& {[C]=\left[-\left[K_{\phi \phi}^{S}\right]^{-1}\left[K_{\phi u}^{S}\right][\psi][\omega]^{-1}[0]\right] \quad\{g\}=\left[\begin{array}{c}
{[0]} \\
{[\Psi]^{T}\left\{B_{u}\right\}}
\end{array}\right]}
\end{aligned}
$$

$\left\{x_{0}\right\}$ is the initial conditions vector.

In (36), the time variable $t$ appears explicitely. The dynamic system (33) can also be represented in the frequency domain considering an harmonic input. 


\subsection{Quasi-static correction}

As the size of the state system depends on the number of modes, the control input also strongly depends on it. Considering the first few modes in the numerical model would not characterize the dynamic response of the real structure. Then, the deduced active control input is not accurate. Therefore, a quasi-static correction must be introduced to improve the model. It consists in adding a static contribution of residual modes to the transfer function of the system. In this section, we briefly describe this method. Details are given in Preumont [27].

The open loop case, where the actuators are not used, is now considered.

(31) is converted into the frequency domain using Fourier's transform, where the piezoelectric effect is neglected:

$$
\left(-\Omega^{2}\left[M_{u u}\right]+\left[K_{u u}\right]\right)\{Q\}=\{L\}
$$

and:

$$
\left\{Q_{\phi}^{S}\right\}=-\left[K_{\phi \phi}^{S}\right]^{-1}\left[K_{\phi u}^{S}\right]\left(-\Omega^{2}\left[M_{u u}\right]+\left[K_{u u}\right]\right)^{-1}\{L\}=[G(\Omega)]\{L\}
$$

where $\{Q\},\{L\}$ and $\left\{Q_{\phi}^{S}\right\}$ are respectively the Fourier's transformed of $\left\{q_{u}\right\},\left\{B_{u}\right\}$ and $\left\{q_{\phi}^{S}\right\} .[G(\Omega)]$ is called the transfer matrix of the system, and is given by:

$$
[G(\Omega)]=-\left[K_{\phi \phi}^{S}\right]^{-1}\left[K_{\phi u}^{S}\right]\left(-\Omega^{2}\left[M_{u u}\right]+\left[K_{u u}\right]\right)^{-1}
$$

In the same way, the Fourier's transform applied to (33) leads to:

$$
-\Omega^{2} A_{n}+\omega_{n}^{2} A_{n}=\{\psi\}^{T}\{L\}
$$

and:

$$
\left\{Q_{\phi}^{S}\right\}=-\left[K_{\phi \phi}^{S}\right]^{-1}\left[K_{\phi u}^{S}\right] \sum_{n=1}^{\infty}\left\{\psi_{n}\right\}\left\{\psi_{n}\right\}^{T}\left(\omega_{n}^{2}-\Omega^{2}\right)^{-1}\{L\}
$$

where $\{A\}$ is the Fourier's transformed of $\{\alpha\}$. Comparing (41) and (44), we obtain a new expression for $[G(\Omega)]$ :

$$
[G(\Omega)]=-\left[K_{\phi \phi}^{S}\right]^{-1}\left[K_{\phi u}^{S}\right] \sum_{n=1}^{\infty}\left\{\psi_{n}\right\}\left\{\psi_{n}\right\}^{T}\left(\omega_{n}^{2}-\Omega^{2}\right)^{-1}
$$

Assuming that the structure has no rigid body modes when $\Omega=0$, we have the "modal expansion of the static matrix":

$$
[G(0)]=-\left[K_{\phi \phi}^{S}\right]^{-1}\left[K_{\phi u}^{S}\right]\left[K_{u u}\right]^{-1}=-\left[K_{\phi \phi}^{S}\right]^{-1}\left[K_{\phi u}^{S}\right] \sum_{n=1}^{\infty}\left\{\psi_{n}\right\}\left\{\psi_{n}\right\}^{T} / \omega_{n}^{2}(46)
$$

For a frequency $\Omega$ lower than a limit $\Omega_{b}$, and if the $m$ first modes are selected such that $\Omega_{b}<<\omega_{m}$, the contribution of the high frequencies can be restrained to its static part:

$$
\begin{gathered}
{[G(\Omega)] \approx-\left[K_{\phi \phi}^{S}\right]^{-1}\left[K_{\phi u}^{S}\right]\left(\sum_{n=1}^{m}\left\{\psi_{n}\right\}\left\{\psi_{n}\right\}^{T}\left(\omega_{n}^{2}-\Omega^{2}\right)^{-1}\right.} \\
\left.+\sum_{n=m+1}^{\infty}\left\{\psi_{n}\right\}\left\{\psi_{n}\right\}^{T} / \omega_{n}^{2}\right)
\end{gathered}
$$


Using (46), into (47) the last term corresponding to the high frequency modes does not appear explicitely:

$$
\begin{aligned}
{[G(\Omega)] \approx-} & {\left[K_{\phi \phi}^{S}\right]^{-1}\left[K_{\phi u}^{S}\right]\left(\sum_{n=1}^{m}\left\{\psi_{n}\right\}\left\{\psi_{n}\right\}^{T}\left(\omega_{n}^{2}-\Omega^{2}\right)^{-1}\right.} \\
& \left.+\left[K_{u u}\right]^{-1}-\sum_{n=1}^{m}\left\{\psi_{n}\right\}\left\{\psi_{n}\right\}^{T} / \omega_{n}^{2}\right)
\end{aligned}
$$

and if the natural damping is added:

$$
\begin{gathered}
{[G(\Omega)] \approx-\left[K_{\phi \phi}^{S}\right]^{-1}\left[K_{\phi u}^{S}\right]\left(\sum_{n=1}^{m}\left\{\psi_{n}\right\}\left\{\psi_{n}\right\}^{T}\left(\omega_{n}^{2}+\delta_{n} \omega_{n} j \Omega-\Omega^{2}\right)^{-1}\right.} \\
\left.+\left[K_{u u}\right]^{-1}-\sum_{n=1}^{m}\left\{\psi_{n}\right\}\left\{\psi_{n}\right\}^{T} / \omega_{n}^{2}\right)
\end{gathered}
$$

The two last terms in (49) represent the quasi-static correction. Neglecting these additional terms can lead to substantial errors in the prediction of the open loop zeros and on the performance of the control system. It will be discussed in examples in the next section.

\subsection{Control law and observer}

In order to actively control vibrations, a linear quadratic control method, including a state observer, is used in this work. Assuming that the state equation is controllable, the control law may be written as:

$$
\left\{q_{\phi}^{A}\right\}=-[K]\{x\}
$$

which minimizes a cost function given by:

$$
J_{\phi}=1 / 2 \int_{0}^{\infty}\left(\{x\}^{T}[Q]\{x\}+\left\{q_{\phi}^{A}\right\}^{T}[R]\left\{q_{\phi}^{A}\right\}\right) d t
$$

$[R]$ is a positive matrix and $[Q]$ is a positive semidefinite matrix. The optimal solution is

$$
[K]=[R]^{-1}[B]^{T}[P]
$$

where $[P]$ satisfies the Riccati equation:

$$
[A]^{T}[P]+[P][A]-[P][B][R]^{-1}[B]^{T}[P]+[Q]=0
$$

The choice of $[Q]$ and $[R]$ is not easy [4]. In the following applications, $[Q]$ is chosen so that $\{x\}^{T}[Q]\{x\}$ represents the mechanical energy. The components of $[R]$ are chosen using the following statement: the maximal values of $\left\{q_{\phi}^{A}\right\}$ are less than the maximal admissible values of the piezoelectric materials.

In order to be implemented, the optimal state control law needs knowledge of the state vector $\{x\}$. This knowledge is not complete since only the output voltages in $\{y\}$ are observed. Assuming that the state system verifies the observability criteria, an estimation $\{\hat{x}\}$ is computed using a Luenberger observer [30] which is thus:

$$
\frac{d}{d t}\{\hat{x}\}=[A]\{\hat{x}\}+[B]\left\{q_{\phi}^{A}\right\}+[L](\{y\}-[C]\{\hat{x}\})+\{g\}
$$


where $[L]$ is the observance gain matrix. It is chosen so that the real part of the eigenvalues of $[A]-[L][C]$ are negative. Consequently, the control law applied to the actuators becomes:

$$
\left\{q_{\phi}^{A}\right\}=-[K]\{\hat{x}\}
$$

\section{Numerical examples}

The finite element used here was validated in [28]. In this section, we present four applications about active control of rectangular plates with piezoelectric patches. The construction of the control and observer is done using MATLAB. As in experimental applications $[14,16]$ active piezoelectric patches are distributed, the following tests do not deal with piezoelectric actuators and sensors bonded on the whole plate. Examples of this kind of active configuration can be found in [28]. Finally, in all tests, the used meshes are obtained from a convergence study.

The four tests are described below:

- test 1:

- simply supported isotropic plate

- uncollocated sensor and actuator

- each device modeled with two piezoelectric patches

- mesh: 304 elements using 6 piezoelectric elements per device

- release test

- test 2:

- clamped free isotropic plate

- uncollocated sensor and actuator

- each device modeled with two piezoelectric patches

- mesh: 304 elements using 6 piezoelectric elements per device

- release test, load step, harmonic load

- test 3:

- clamped free isotropic plate

- collocated sensor and actuator

- each device modeled with two piezoelectric patches

- mesh: 304 elements using 6 piezoelectric elements per device

- release test

- test 4:

- clamped free graphite epoxy plate

- collocated embedded sensor and actuator

- release test

- mesh: 100 elements using 1 piezoelectric element per device

- 1, 2 or 4 piezoelectric devices

In the first three tests, each device is made with two piezoelectric patches bonded symmetrically to the structure and in opposition phase in order to limit the study to 
Table 1. geometrical characteristics of the plate and the piezoelectric patch

\begin{tabular}{lll}
\hline & Plate & Piezoelectric \\
\hline Length $(\mathrm{m})$ & 0.3 & 0.03 \\
With $(\mathrm{m})$ & 0.2 & 0.02 \\
Thickness $(\mathrm{m})$ & 0.001 & $1 e-4$ \\
\hline
\end{tabular}

Table 2. Mechanical characteristics of piezoelectric patch Zirconate P1 88

\begin{tabular}{ll}
\hline$\rho\left(\mathrm{kg} / \mathrm{m}^{3}\right)$ & 7650 \\
$C_{11}=C_{22}(\mathrm{GPa})$ & 132.2 \\
$C_{12}=C_{21}(\mathrm{GPa})$ & 82.3 \\
$C_{13}=C_{23}=C_{31}=C_{32}(\mathrm{GPa})$ & 83.7 \\
$C_{33}(\mathrm{GPa})$ & 120 \\
$C_{44}=C_{55}(\mathrm{GPa})$ & 29.5 \\
$C_{66}(\mathrm{GPa})$ & 25 \\
$\epsilon_{0}(\mathrm{~F} / \mathrm{m})$ & $8.85 e^{-12}$ \\
$\epsilon_{11}=\epsilon_{22}$ & $1440 \epsilon_{0}$ \\
$\epsilon_{33}$ & $837 \epsilon_{0}$ \\
$e_{31}=e_{32}\left(C m^{-2}\right)$ & -4.3 \\
$e_{33}\left(C m^{-2}\right)$ & 16.7 \\
$e_{15}\left(\mathrm{Cm}^{-2}\right)$ & 11.8 \\
maximal value of $\left(q_{\phi}\right)(V)$ & 150 \\
\hline
\end{tabular}

Table 3. Mechanical characteristics of the elastic plate (tests 1,2 and 3)

\begin{tabular}{ll}
\hline$\rho\left(\mathrm{kg} / \mathrm{m}^{3}\right)$ & 7870 \\
$\mathrm{E}(\mathrm{GPa})$ & 207 \\
$\nu$ & 0.292 \\
\hline
\end{tabular}

bending motions. The electrical potential is set to zero on all the interface between elastic layer and piezoeletric patches.

In all tests, plates have the same size and same piezoelectric material is used. Mechanical and geometrical caracteristics of each material are given tables 1,2,3 and 6.

\subsection{Test 1: active control of a simply supported plate}

The active control of a simply supported plate is studied in the case of a release test. There is one actuator and one sensor located near a fixed edge (as shown figure 3). Indeed, the values of strains are highest for this location and consequently the piezoelectric patches will be more effective for sensing and actuating. The initial conditions are deduced from the initial load, $\vec{F}(t=0)=10 \vec{e}_{3}$, applied to the middle of the plate.

Only the first five eigenmodes are taken into account because this kind of load 


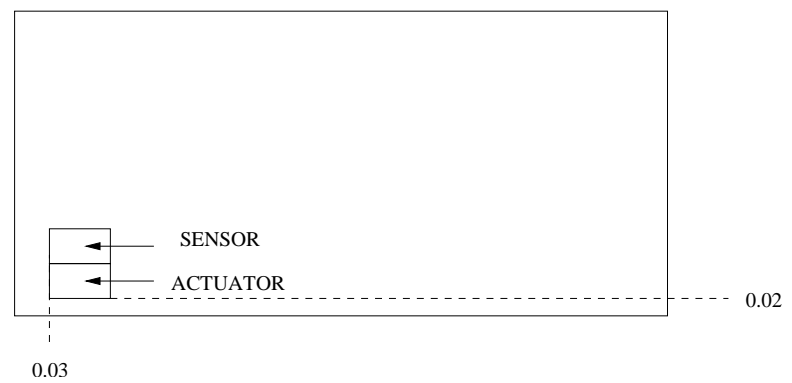

Figure 3. Tests 1 and 2 : plate with one actuator and one sensor uncollocated

excites essentially the first frequency (frequencies: $87.92 \mathrm{~Hz}, 168.97 \mathrm{~Hz}, 270.47 \mathrm{~Hz}$, $304.41 \mathrm{~Hz}, 351.60 \mathrm{~Hz}$ ). The sensor output in open and closed loop is plotted in figures 4 and 5. The amplitude decay of the open loop response comes from natural damping, while that of the closed loop system comes mainly from the feedback control. Figure 6 shows the required input voltage for the active control. If $[R]$ is chosen smaller, the maximal values of the input voltage will be higher and the control will be more effective.

To show that the use of five modes is enough, the mechanical energy (normalized with

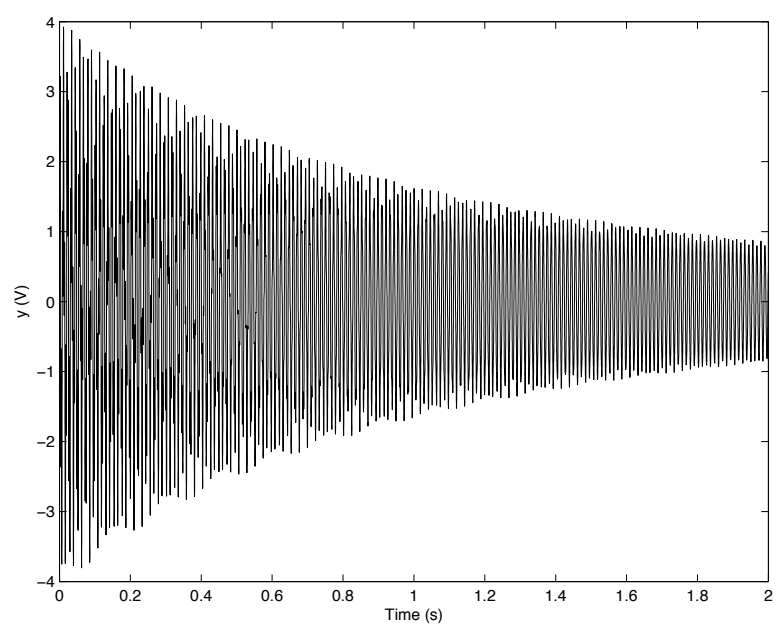

Figure 4. Test 1: the sensor output for the open loop case

its initial value) for each mode is plotted in figure 7 in the closed loop case. The first mode is the most excited one.

A validation of the $\mathrm{FE}$ active control tool can be done on this test because analytical solution for this problem is known [25]. For the FE simulations, stiffness and mass of the piezoelectric patches are neglected. The relative error for the mechanical energy between FE solution and analytical solution is less than $0.4 \%$.

Finally, influence of the mechanical caracteristics of the piezoelectric patches is evaluated. The total mechanical energy is plotted in figure 8 and the two curves are similar. 


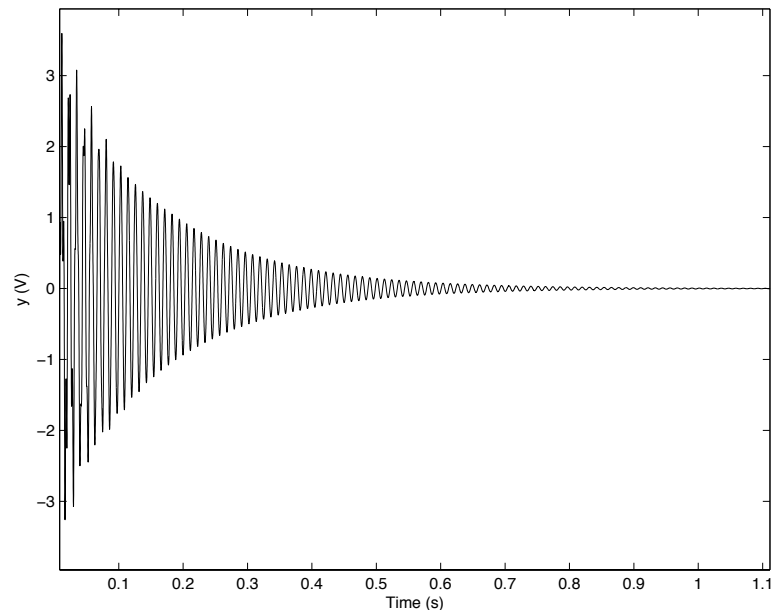

Figure 5. Test 1: the sensor output for the closed loop case

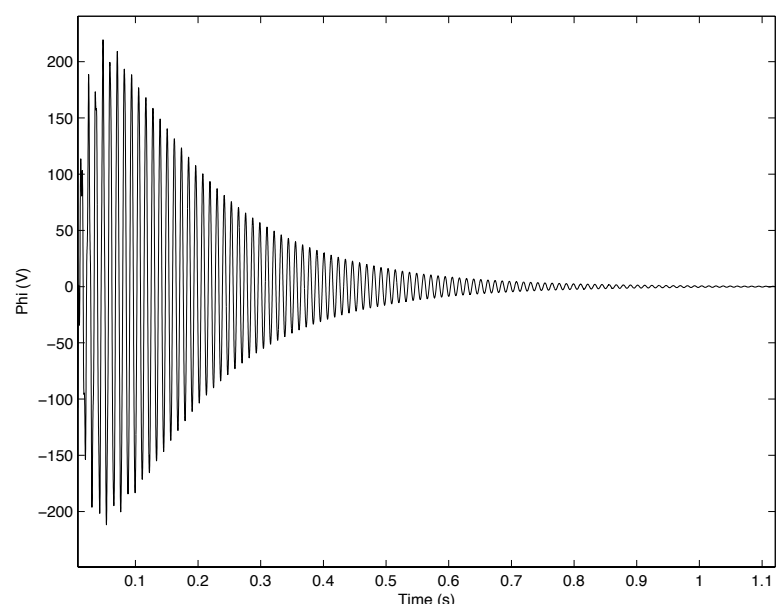

Figure 6. Test 1: the actuator input

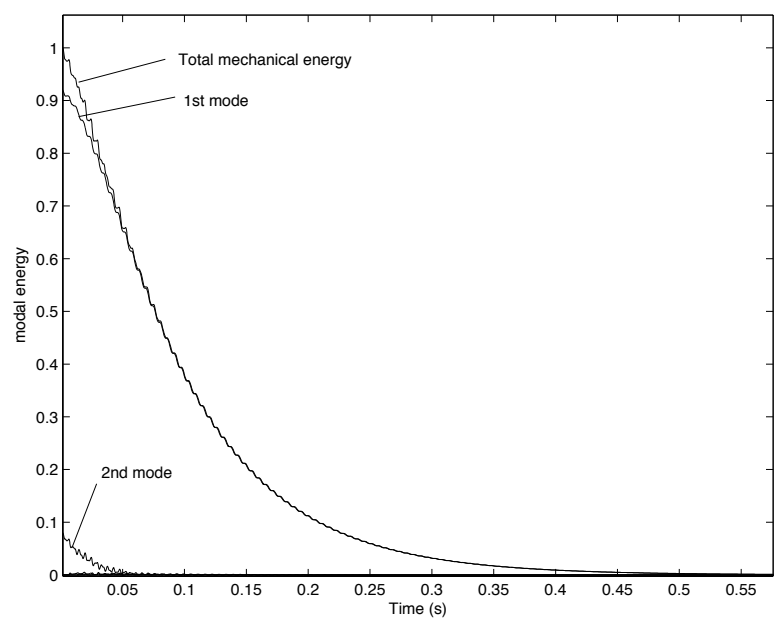

Figure 7. Test 1: the mechanical energy in closed loop, for each mode 


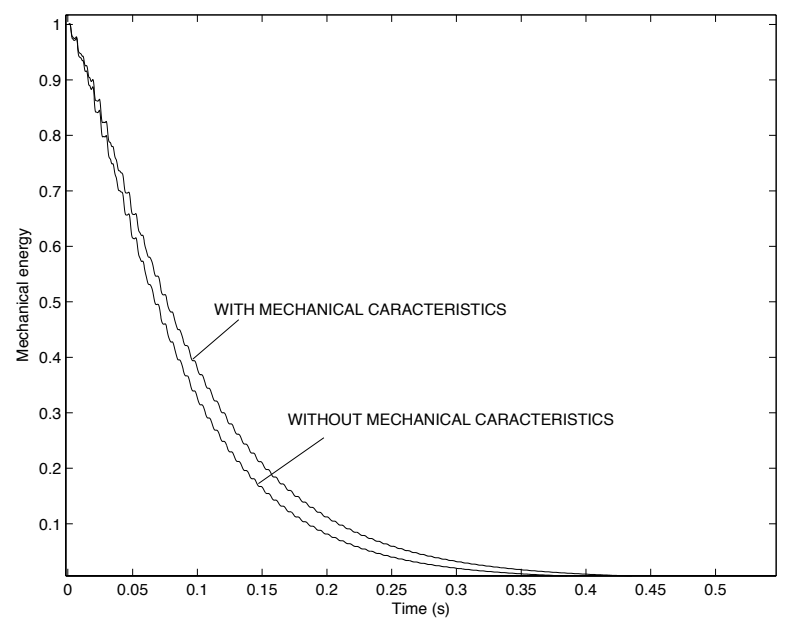

Figure 8. Test 1: the mechanical energy in closed loop, using or not mechanical caracteristics of piezoelectric patches

4.2. Test 2: active control of a clamped-free plate with actuator and sensor uncollocated

In this test, the plate is clamped at its edges $x=0$ and $x=L$, and equipped with one actuator and one sensor uncollocated (see figure 3). Their location is the same as in the previous test. Several loads are applied to the structure. For each simulation, the first eight modes are used (frequencies: $60.55 \mathrm{~Hz}, 84.61 \mathrm{~Hz}, 166.79 \mathrm{~Hz}, 194.55 \mathrm{~Hz}, 202.45$ $\mathrm{Hz}, 324.12 \mathrm{~Hz}, 327.57 \mathrm{~Hz}, 368.01 \mathrm{~Hz}$ ). The bode diagram is presented figure 9 with and without the quasi-static correction. This additional term gives the same curve than the usual approach except for $\omega>\omega_{8}$.

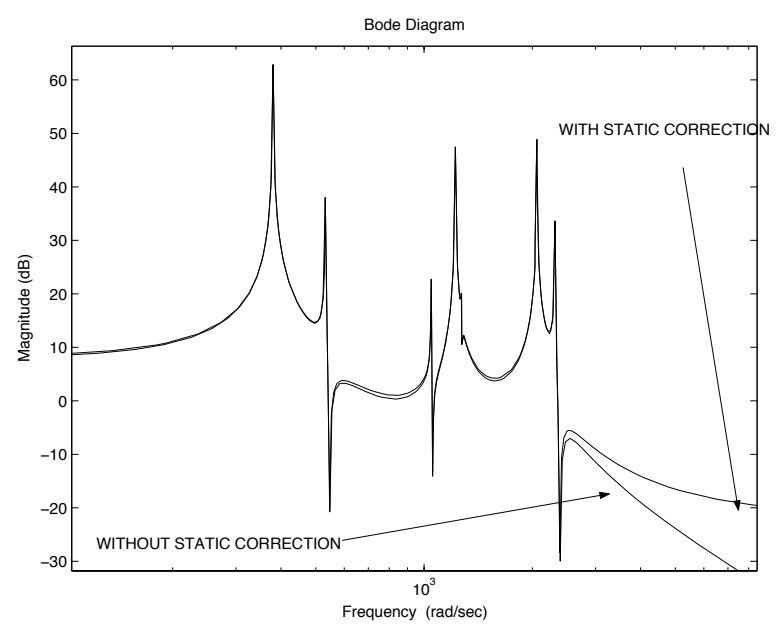

Figure 9. Test 2: the bode diagram for the clamped-free plate

4.2.1. The release test Initial conditions are similar to those used in the last section: they derive from an initial load $\vec{F}(t=0)=10 \vec{e}_{3}$ applied to the middle of the plate. For this excitation, the use of eight modes obviously leads to a right model. The sensor 
output in open and closed loop are shown figures 10 and 11. The actuator input is plotted in figure 12. For this kind of structure, the active control is very effective: in less than 1 seconde, the vibrations of the plate disappear.

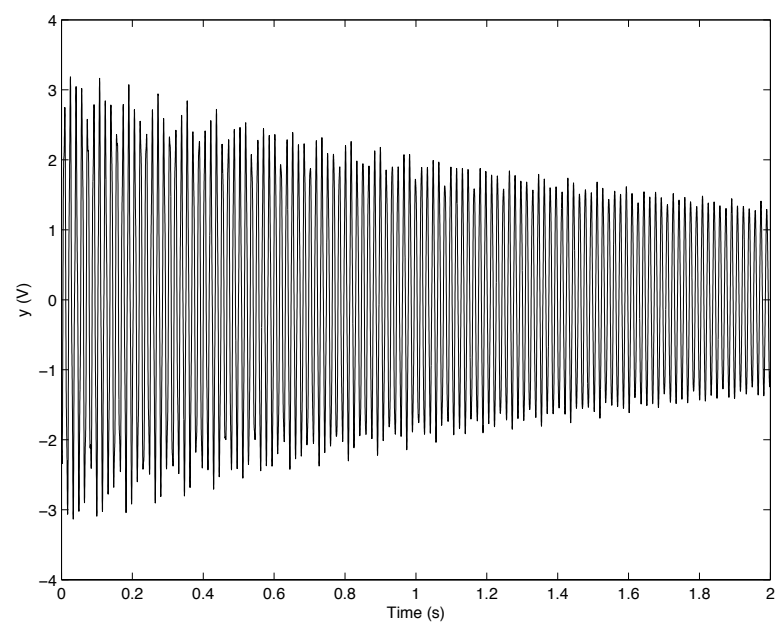

Figure 10. Test 2: initial conditions: the sensor output for the open loop case

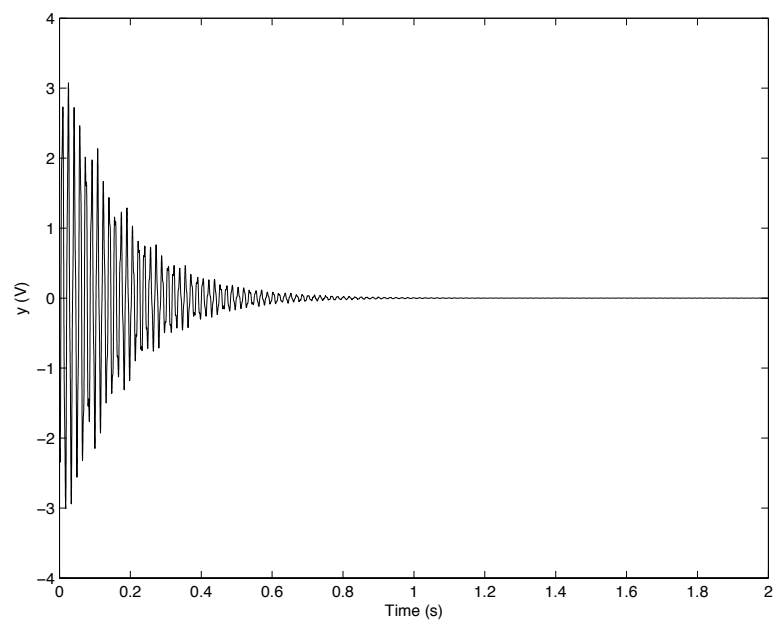

Figure 11. Test 2: initial conditions: the sensor output for the closed loop case

4.2.2. The load step The structure is now subjected to a load step at the middle of the plate (as shown figure 13). The sensor output in open and closed loops, and the actuator input are presented figures 14, 15, 16. The effectiveness of the active control again is shown.

In order to discuss the use of the quasi-static correction in open and closed loops, the following error is presented in table 4:

$$
100\left(\|y\|-\left\|y^{Q S C}\right\|\right) /\left\|y^{Q S C}\right\|
$$




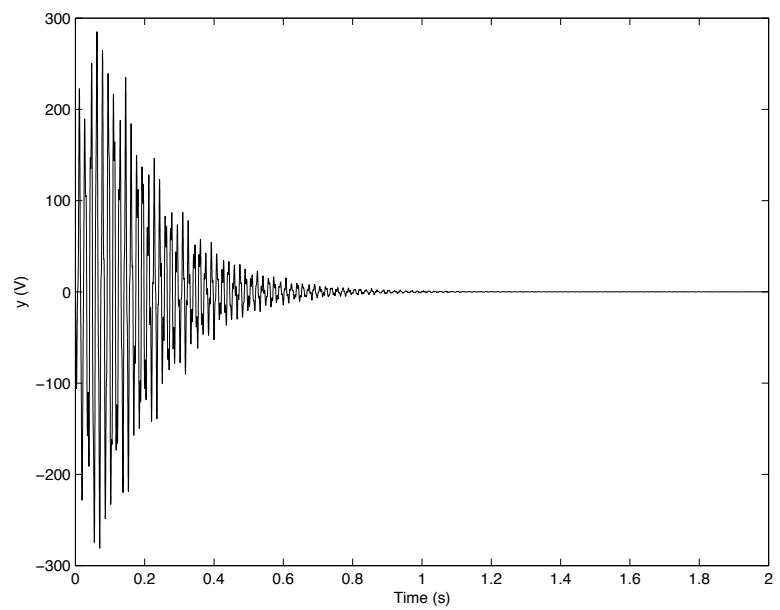

Figure 12. Test 2: initial conditions: the actuator input

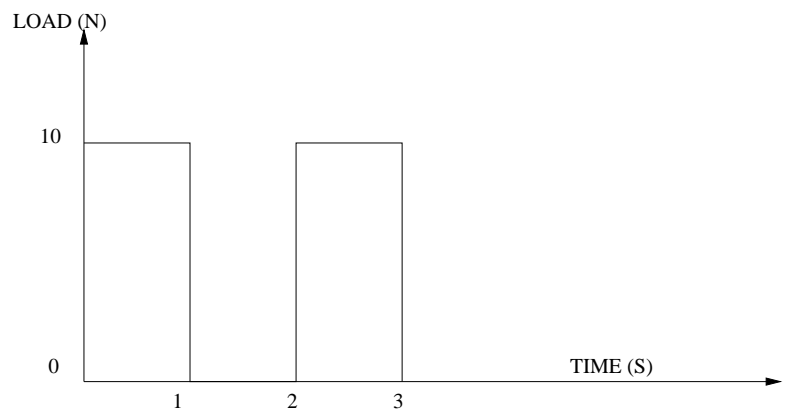

Figure 13. The step load

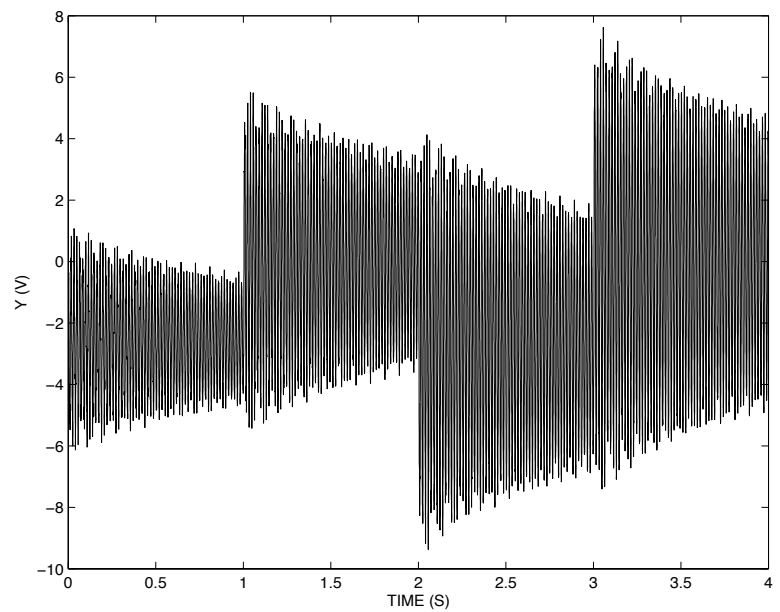

Figure 14. Test 2: step load: the sensor output for the open loop case

where $y^{Q S C}$ and $y$ are respectively the sensor output taking into account or neglecting the quasi-static term. As the active input actuates all the modes, the error is bigger in closed loop than in open loop. Results show that the use of the correction term is required if few modes are used. 


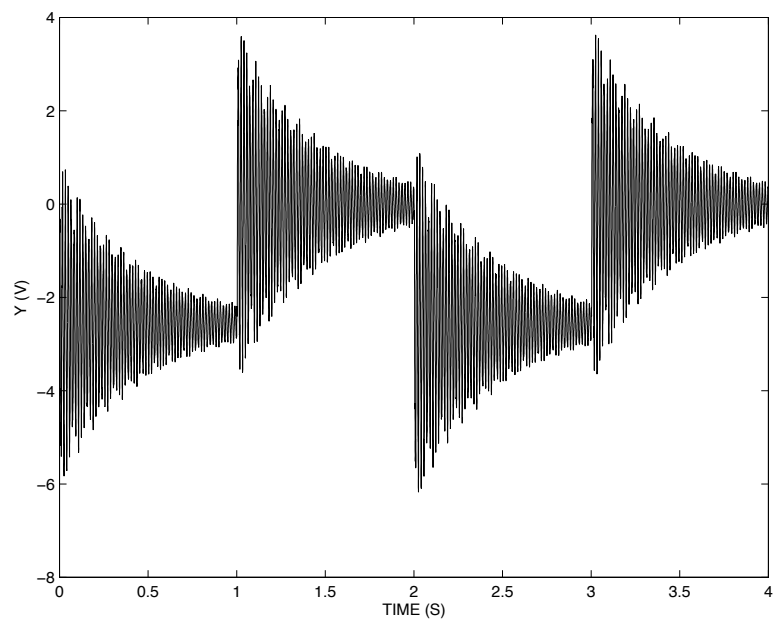

Figure 15. Test 2: step load: the sensor output for the closed loop case

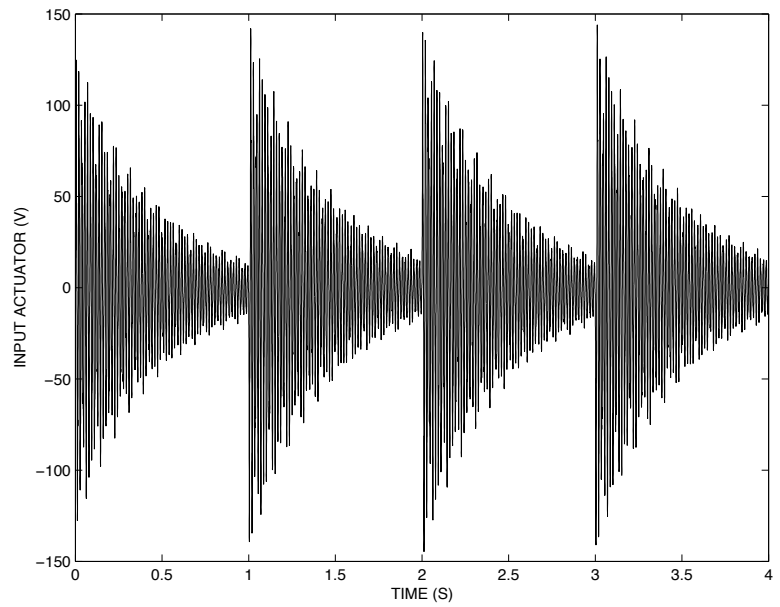

Figure 16. Test 2: step load: the actuator input

Table 4. Step load: error for sensor output.

\begin{tabular}{lll}
\hline Number of modes & Open loop & Closed loop \\
\hline 4 & $-6.60 \%$ & $-19.29 \%$ \\
5 & $-6.31 \%$ & $-18.46 \%$ \\
6 & $-6.95 \%$ & $-20.33 \%$ \\
7 & $-3.77 \%$ & $11.05 \%$ \\
8 & $1.75 \%$ & $5.09 \%$ \\
\hline
\end{tabular}

4.2.3. The harmonic load The structure is now subjected to a persistent harmonic load applied at the middle of the plate and equals to: $10 \cos \left(\omega_{F} t\right)$ where $\omega_{F}=120 \mathrm{rad}_{\mathrm{s}} \mathrm{s}^{-1}$. The use of the quasi-static correction is again studied table 5. Here, even if we consider 8 modes, its use is required because of the load. Results are plotted in figures (17), (18), (19) and vibrations are controled in less than 2 seconds. 
Table 5. Harmonic load: error for sensor output.

\begin{tabular}{lll}
\hline Number of modes & Open loop & Closed loop \\
\hline 4 & $29.30 \%$ & $49.66 \%$ \\
5 & $27.79 \%$ & $47.38 \%$ \\
6 & $31.26 \%$ & $53.14 \%$ \\
7 & $-12.03 \%$ & $-21.39 \%$ \\
8 & $-5.92 \%$ & $-10.59 \%$ \\
\hline
\end{tabular}

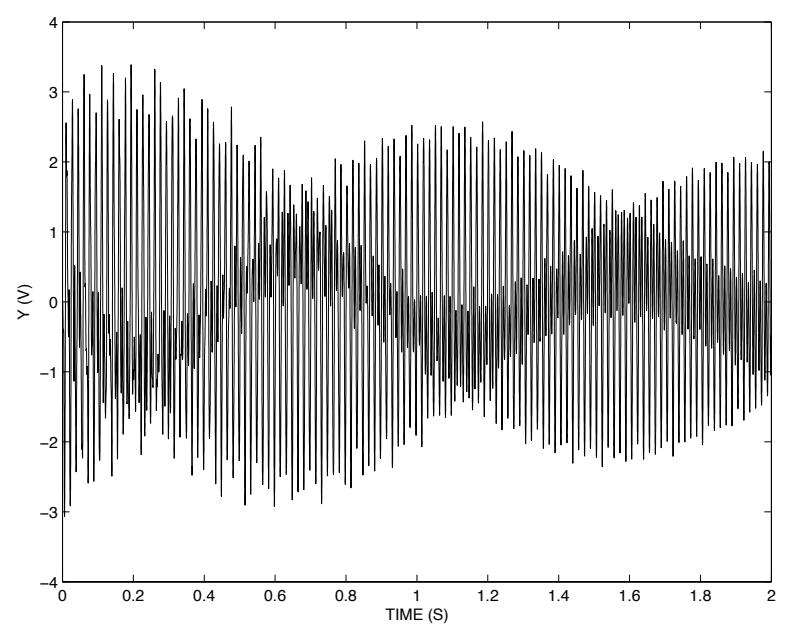

Figure 17. Test 2: harmonic load: the sensor output for the open loop case

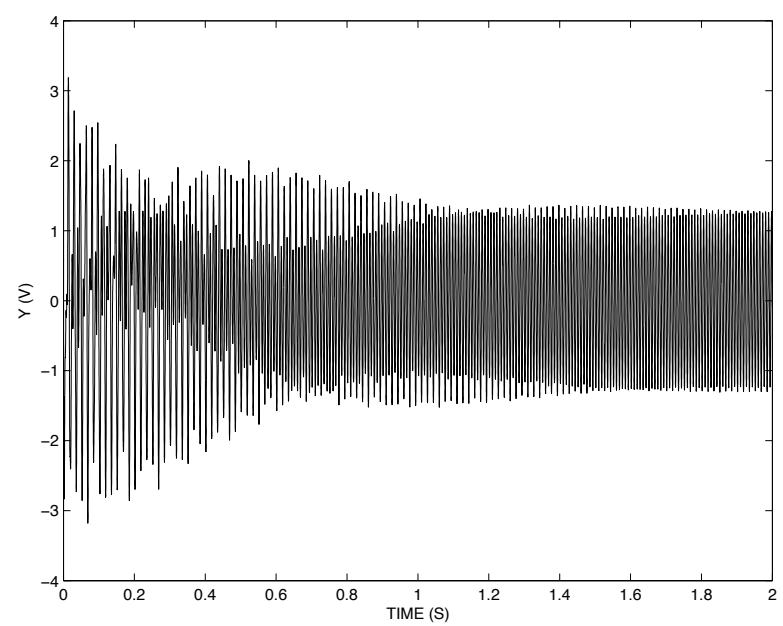

Figure 18. Test 2: harmonic load: the sensor output for the closed loop case

\subsection{Test 3: active control of a clamped-free plate with collocated actuator and sensor}

In this section, actuator and sensor are collocated near a fixed edge (see figure 20). They are again made with two piezoelectric patches bonded symmetrically to the plate. The electric potential at the interfaces between actuator the sensor is set to zero. This configuration is compared with the uncollocated one (see figure 3 ) in the case of a release 


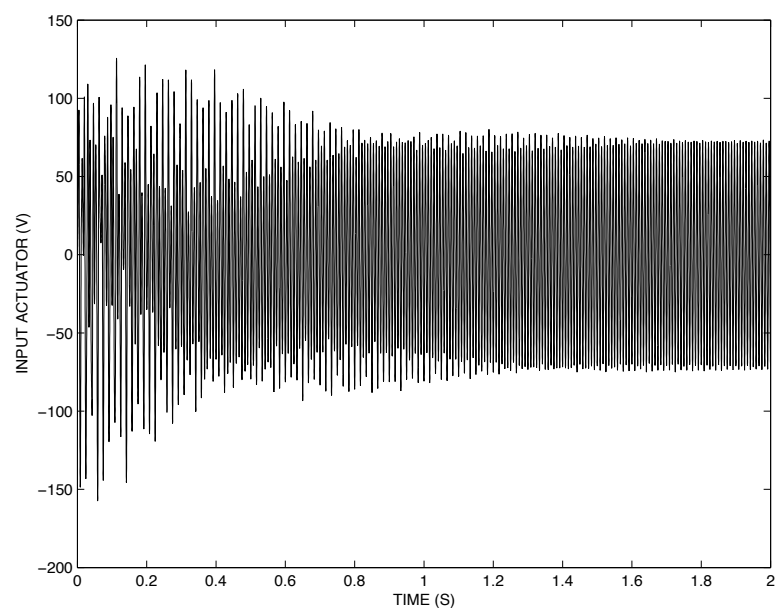

Figure 19. Test 2: harmonic load: the actuator input

test, using the mechanical energy (see figure (21)). The shapes of the two curves are similar. Here, the non collocated active configuration attenuates a little bit quickly the vibrations.
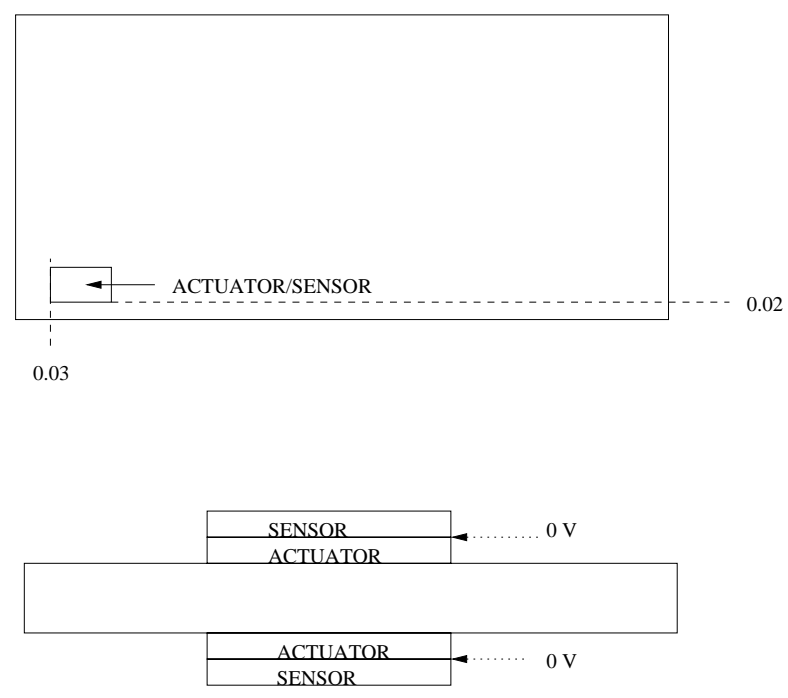

Figure 20. Test 3: the sensor and actuator collocated

4.4. Test 4: active control of a clamped-free laminated plate with embedded collocated actuators and sensors

The active control of a graphite-epoxy plate is now studied. Some papers, see for instance $[16,17,11,12]$ are focused on the use of several actuators and sensors. Therefore, three active configurations are compared (figure 22):

-case 1: with device 1

-case 2: with devices 1 and 2

-case 3: with the four devices. 


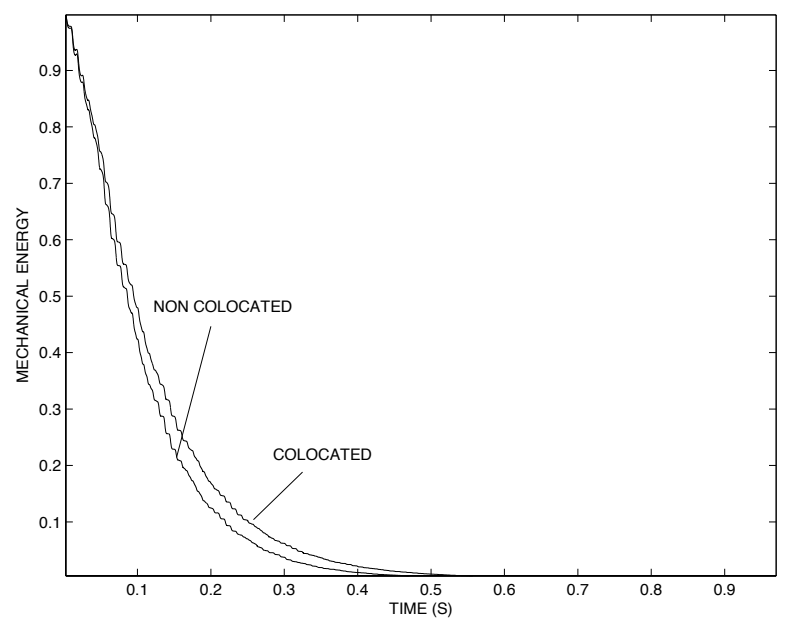

Figure 21. Test 3: mechanical energy

Table 6. Mechanical and geometrical characteristics of one Graphite/Epoxy layer (test 4)

Thickness $(\mathrm{m})$

$\rho\left(\mathrm{kg} / \mathrm{m}^{3}\right)$

$E_{1}(\mathrm{GPa})$

$E_{2}=E_{3}(\mathrm{GPa})$

$G_{12}=G_{13}(\mathrm{GPa})$

$G_{23}(\mathrm{GPa})$

$\nu_{12}=\nu_{13}=\nu_{23}$
$1 e^{-4}$

1600

150

9

7.1

2.5

0.3

The laminate is made of ten plies $(45 /-45 / 0 / 45 /-45)_{s}$ with the same thickness. The material properties are given in table 6 . The following sequence is used for the smart devices: $(45 /-45 / \text { piezo0/45/ }-45)_{s}$. The sensors and actuators are respectively located in the third and eighth layer The electric potential is set to zero for the interfaces 2 and 10 .

When several actuators are used, the matrix $[R]$ of the LQR algorithm is chosen so that the electric potential of each actuator will be maximal.

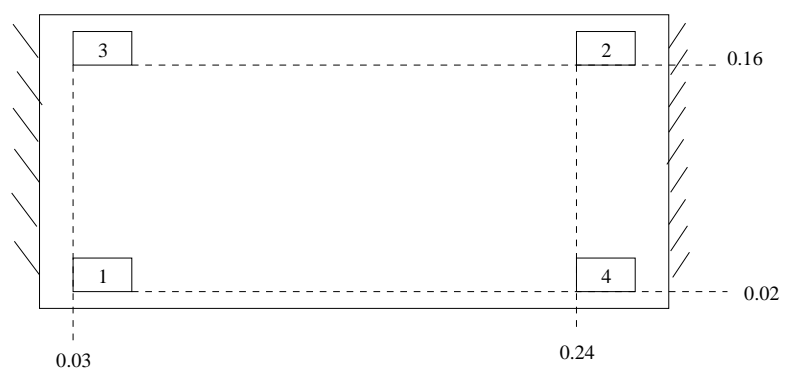

Figure 22. Test 4: location of the four active embedded devices

The simulations are presented in the case of the following initial conditions: $F=10 N$ at the middle of the plate. Only the first 6 frequencies are used: 66.05 
Table 7.

\begin{tabular}{lll}
\hline Case & Time response of sensor $1(\mathrm{~s})$ & Total electrical quantity $\left(V^{2} s\right)$ \\
\hline 1 & 3.52 & 917 \\
2 & 1.77 & 932 \\
3 & 1.03 & 1101 \\
\hline
\end{tabular}

$\mathrm{Hz}, 105.61 \mathrm{~Hz}, 183.14 \mathrm{~Hz}, 220.71 \mathrm{~Hz}, 245.09 \mathrm{~Hz}, 360.96 \mathrm{~Hz}$. Results are plotted in figures (23), (24), (25) for the case 1 and in figures (26), (27), (28),(29) for the case 2. The curves for case 3 are not presented. In order to compare these three configurations, the response time of sensor 1 and the total electrical quantity used for control defined by:

$$
1 / 2 \int_{0}^{T}\left\{q_{\Phi}^{A}\right\}^{T}\left\{q_{\Phi}^{A}\right\} d t
$$

are presented table 7 . For all cases, the active control is very effective. With respect to case 1 , the time response of sensor 1 decreases when two or four devices are used but, the total electrical potential quantity increases, especially for case 3 . The optimal number of actuators/sensors for active control is not easy to define. The readers can find some comments about the objective function for optimization in [25].

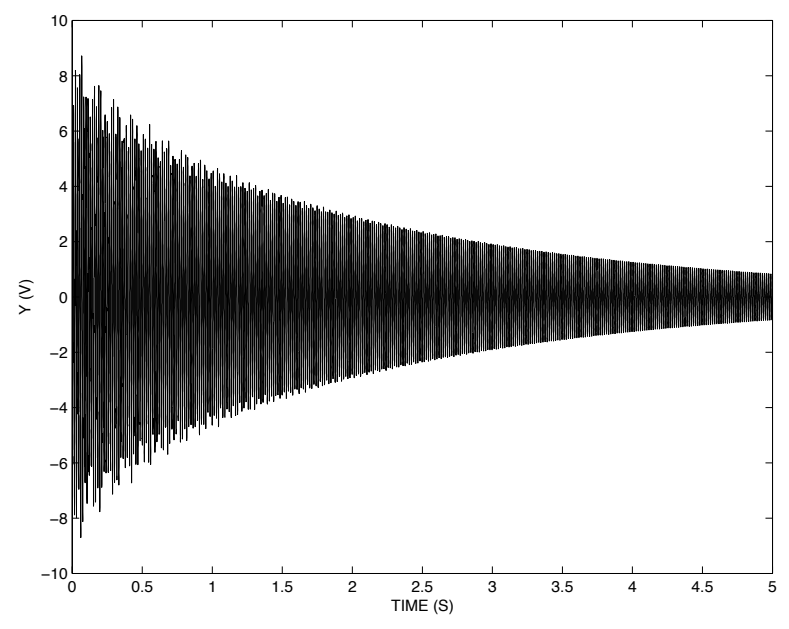

Figure 23. Test 4: case 1: the sensor output 1 for the open loop case

\section{Conclusion}

In this paper a new finite element tool for active control of laminated plates has been presented. It consists of an eight node plate $\mathrm{FE}$ with one electrical potential degree of freedom for each interface of piezoelectric layers. The displacement approximation is the usual FSDT theory but, it is combined with a 'field compatibility' methodology in order to avoid the transverse shear locking of thin plates. 


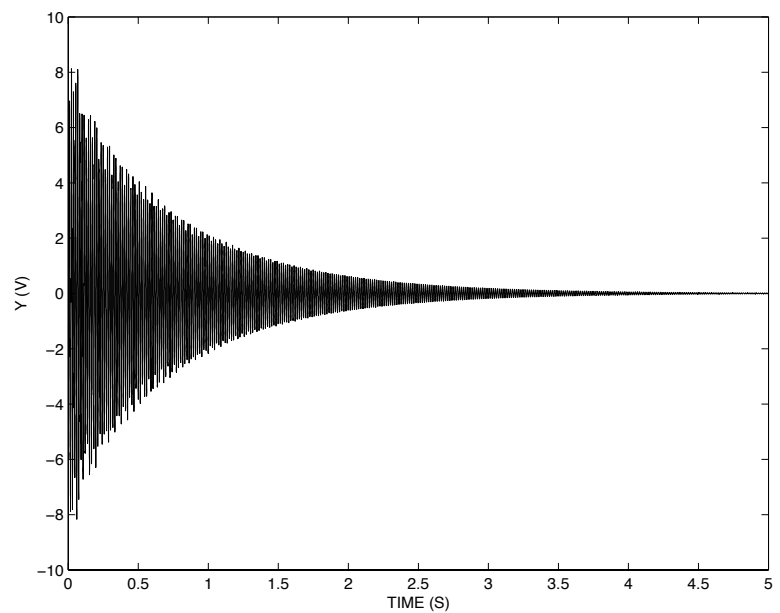

Figure 24. Test 4: case 1: the first sensor output for the closed loop case

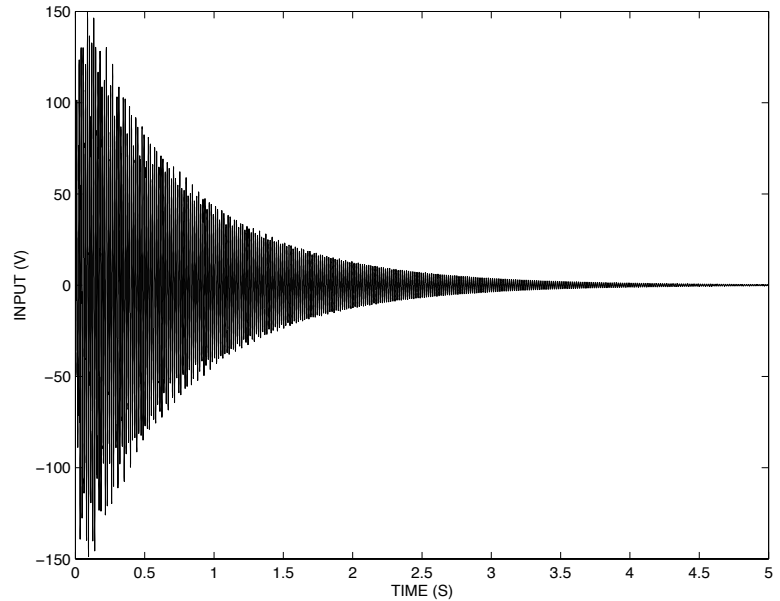

Figure 25. Test 4: case 1: the actuator input

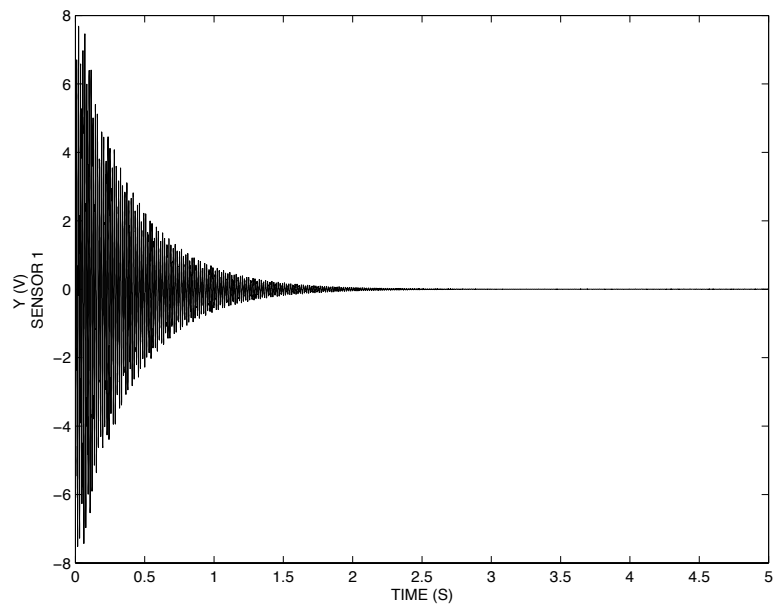

Figure 26. Test 4: case 2: the first sensor output for the closed loop case 


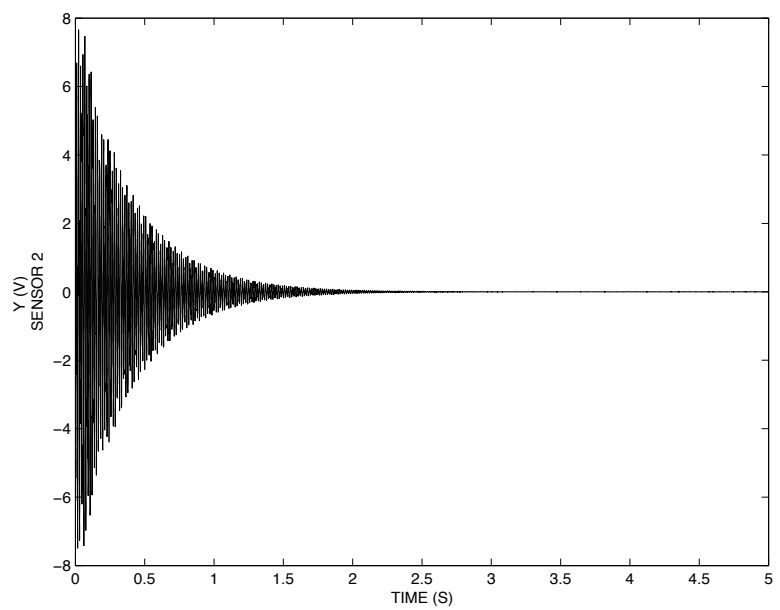

Figure 27. Test 4: case 2: the second sensor output for the closed loop case

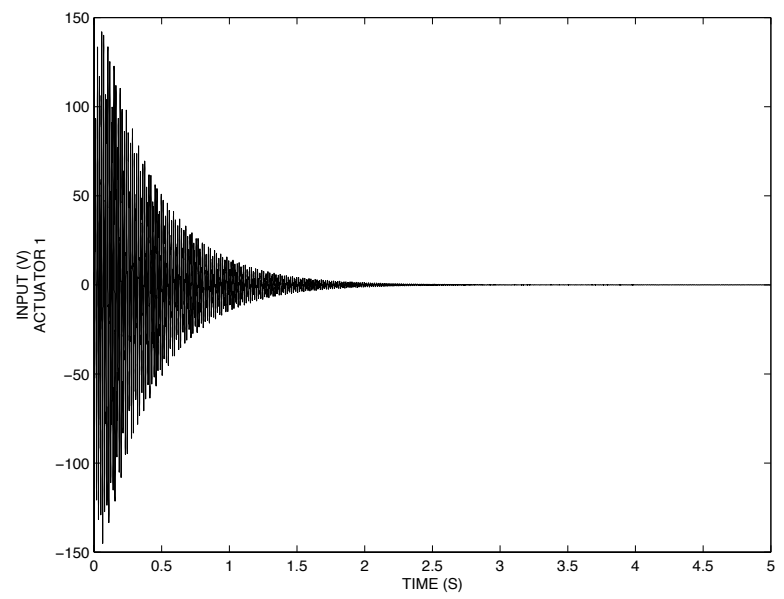

Figure 28. Test 4: case 2: the first actuator input

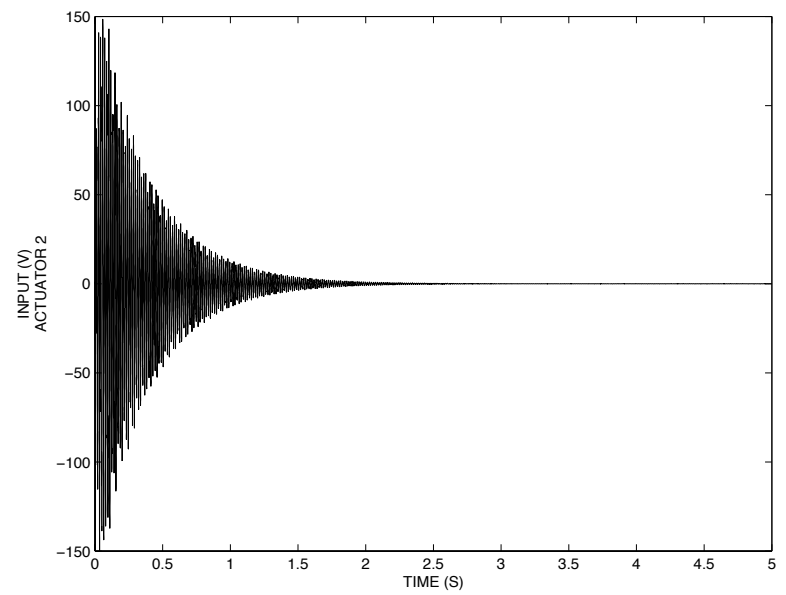

Figure 29. Test 4: case 2: the second actuator input

A LQR control method including a state observer has been used in this work. 
Simulations show that the active control of plates can be very effective but, also that a quasi-static correction can be essential to accurately model the dynamic of the structure, according to the truncation of the modal basis.

This simple and effective numerical tool allows to simulate active control of plates for many smart configurations: piezoelectric actuators and sensors collocated/uncollocated, embedded/bonded, distributed/on the overall structure. It can also be easily used to solve structural optimization problems dealing with the effectiveness of active control like the number, size and locations of piezoelectric patches. This subject will be studied in future investigation.

\section{References}

[1] Wang S Y, Quek S T et al 2001 Vibration control of smart piezoelectric composite platesSmart Mater. Struct. 10 637-644

[2] Moita J M S, Correia I F P et al 2004 Active control of adaptive laminated structures with bonded piezoelectric sensors and actuators Comput. Struct. 82 1349-1358

[3] Moita J M S, Mota Soares C M et al 2005 Active control of forced vibrations in adaptive structures using a higher order model Compos. Struct. 71 349-355

[4] Ang K K, Wang S Y et al 2002 Weighted energy linear quadratic regulator vibration control of piezoelectric composite plates Smart Mater. Struct. 11 98-106

[5] He X Q, Ng T Y et al 2002 Active control of FGM plates with integrated piezoelectric sensors and actuators Int. J. Solids Struct. 38 1641-1655

[6] Tzou H S, Tseng C I 1990 Distributed piezoelectric sensor/actuator design for dynamic measurement/control of distributed parameter systems: a piezoelectric finite element approach J. Sound Vibr. 138 17-34

[7] Balamurugan V, Narayanan S 2001 Shell finite element for smart piezoelectric composite plate/shell structures and its application to the study of active vibration control Finite Elements in Analysis and Design 37 713-738

[8] Raja S, Sinha P K et al 2002 Influence of one and two dimensional piezoelectric actuation on active vibration control of smart panels Aeros. Science and Techno. 6 209-216

[9] Wang S Y, Quek S T et al 2004 Dynamic stability of finite element modeling of piezoelectric composite plates Int. J. Solids and Struct. 41 745-764

[10] Chen S H, Wang Z D et al 1997 Active vibration control and suppression for intelligent structures J. Sound Vibr. 200 167-177

[11] Moita J M S, Correia V M F et al 2006 Optimal design in vibration control of adaptive structures using a simulated annealing algorithm Compos. Struct. article in press

[12] Liew K M, He X Q et al 2004 Dynamic analysis of laminated composite plates with piezoelectric sensor/actuator patches using the FSDT mesh-free method Int. J. Mech. Sciences 46 411-431

[13] Chandrashekhara K, Bhatia K 1993 Active buckling control of smart composite plates-finite element analysis Smart Mater. Struct. 2 31-39

[14] Kusculuoglu Z K, Royston T J 2005 Finite element formulation for composite plates with piezoceramic layers for optimal vibration control applications Smart Mater. Struct. 14 11391153

[15] Narayanan S, Balamurugan V 2003 Finite element modelling of piezolaminated smart structures for active vibration control with distributed sensors and actuators J. Sound Vibr. 262 529-562

[16] Dong X J, Meng G et al 2006 Vibration control of piezoelectric smart structures based on system identification technique: numerical simulation and experimental study J. Sound Vibr. 297 680-693 
[17] Caruso G, Galeani S et al 2003 Active vibration control of an elastic plate using multiple piezoelectric sensors and actuators Simul. Model. Practise and Theory 11 403-419

[18] Lim Y H 2003 Finite element simulation of closed loop vibration control of a smart plate under transient loading Smart Mater. Struct. 12 272-286

[19] ChenC Q, Shen Y P 1997 Optimal control of active structures with piezoelectric modal sensors and actuators Smart Mater. Struct. 6 403-409

[20] Zhang H Y, Shen Y P 2006 Vibration suppression of laminated plates with 1-3 piezoelectric fiberreinforced composite layers equipped with interdigitated electrodes Compos. Struct. article in press

[21] Benjeddou A 2004 Modelling and simulation of adaptive structures composites current trends and future directions in: Topping B, Soares $C M$ editors, Progress in computational structures technology, Saxe-Coburg Publications 251-280

[22] Lim Y H, Varadan V V et al 1997 Closed loop finite element modeling of active structural damping in the frequency domain Smart Mater. Struct. 6 161-168

[23] Suleman A, Venkayya V B 1995 A simple finite element formulation for a laminated composite plate with piezoelectric layers J. Intell. Mater. Syst. Struct. 6 776-782

[24] Bruant I, Coffignal G et al 2001 A methodology for determination of piezoelectric actuator and sensor location on beam structures J. Sound Vibr. 243 861-882

[25] Bruant I, Proslier L 2005 Optimal location of actuators and sensors in active vibration control $J$. Intell. Mater. Syst. Struct. 16 197-206

[26] Polit O, Touratier M et al 1994 A new eight-node quadrilateral shear-bedning plate finite element Int. J. Num. Meth. Eng. 37 387-411

[27] Preumont A 1997 Vibration Control of active structures, an introduction Dordrecht: Kluwer Academic Publishers

[28] Polit O, Bruant I 2006 Electric potential approximations for an eight node plate finite element Compos. Struct. 84 1480-1493

[29] Ganapathi M, Polit O et al 1996 A $C^{0}$ eight-node membrane shear bending element for geometrically non linear (static and dynamic) analysis of laminates Int. J. Num. Meth. Eng. 39 3453-3674

[30] Kailath T 1980 Linear Systems Englewwod Cliffs, NJ: Prentice Hall 